Wahyudi dan Maulida — Pengenalan Pola Citra Kain Tradisional Menggunakan GLCM dan KNN

\title{
PENGENALAN POLA CITRA KAIN TRADISIONAL MENGGUNAKAN GLCM DAN KNN
}

\author{
Johan Wahyudi ${ }^{1}$, Ihdahubbi Maulida ${ }^{2)}$ \\ ${ }^{1,2)}$ STMIK Indonesia Banjarmasin \\ Email: johan77@stmik.id ${ }^{1)}$,ihdalhubbimaulida90@gmail.com²)
}

\begin{abstract}
Abstrak
Kain tradisional memiliki pola yang unik, pola tersebut merupakan warisan dari budaya. Beragamnya suku budaya di Indonesia membuat jumlah kain tradisional juga beragam. Beragamnya jenis kain tradisional menyebabkan generasi sekarang kurang mengenali pola kain tradisional yang merupakan warisan dari nenek moyang. Sasirangan merupakan kain tradisional berasal dari kalimantan selatan. Penelitian ini bertujuan mengenali pola sasirangan dari banyaknya pola kain tradisional di Indonesia. Dengan penerapan ektraksi fitur Grey Level Cooccurence Matrices (GLCM) dengan metode klasifikasi menggunakan KNN untuk mencari jarak sehingga mendapatkan tingkat akurasi dari hasil klasifikasi.
\end{abstract}

Kata kunci: Sasirangan, kain tradisional, KNN, GLCM

\begin{abstract}
Traditional cloth has a unique pattern, the pattern is a cultural heritage. The diversity of ethnic groups in Indonesia makes the amount of traditional cloth also varied. The variety of types of traditional cloth causes the current generation to not recognize traditional cloth patterns which are inherited from their ancestors. Sasirangan is a traditional cloth originating from South Borneo. This study aims to identify the sasirangan patterns of the many traditional fabric patterns in Indonesia. With the application of Gray Level Coocurence Matrices (GLCM) feature extraction with the classification method using (k-nearest neighbors) KNN to find the distance so as to obtain the accuracy of the classification results.
\end{abstract}

Keywords: Sasirangan, traditional cloth, KNN, GLCM

\section{PENDAHULUAN}

$\mathrm{S}$ alah satu wujud dari hasil proses budaya adalah penciptaan karya seni dan dimiliki oleh hampir seluruh suku bangsa Indonesia. Kain tradisional Indonesia yang beranekaragam merupakan hasil proses budaya, keanekaragaman kain - kain tradisional dihasilkan oleh perbedaan geografis, flora, fauna, perbedaan gaya hidup dan mata pencaharian[1]. Kain tradiosional Indonesia banyak diminati oleh pasar baik dalam pasar nasional maupun internasional. Motif yang beragam membuat kain tradisional sangat diminati, untuk jenis kain batik saja memiliki lebih dari 181 motif[2]. Selain motif, teknik pengolahan kain tradisional di Indonesia juga beranekaragam. Dengan teknik pengolahan berbeda akan menghasilkan motif yang beragam. Teknik pengolahan ada dengan cara ditenun, celup, lukis dan dicap. Motif pun beragam, dari teknik pengolahan motif pada Keanekaragaman motif kain menjadikan kendala untuk para pedagang dalam menyebutkan jenis motif kain tradisional begitupun untuk generasi bangsa Indonesia juga sangat minim pengetahuan tentang motif-motif kain tradisional karena belum terpusatnya informasi tentang kain tradisional se-Indonesia terutama motif-motif kain tradisional. Klasifikasi secara otomatisasi ini akan dilakukan pada citra kain, ada beberapa metode yang dikembangkan oleh peneliti dalam pengklasifikasian citra digital diantaranya adalah Artificial Neural Network (ANN), Naive Bayes Classifier, k-nearest neighbors (KNN), Support Vector Machine (SVM), Gaussian Mixture Model, Decision Tree(DT), radial basis function (RBF) classifiers, dan Fuzzy Classification[3][4][5]. Untuk ekstraksi fitur, penelitian terkait sudah dilakukan oleh Nurhaida dan kawan - kawan, penelitian tersebut membandingkan ketiga teknik ekstraksi fitur yaitu Gray Level Cooccurrence Matrices (GLCM), Canny Edge Detection dan Gabor. Penelitian ini menunjukkan bahwa GLCM adalah teknik ekstraksi fitur yang paling unggul diantara 
keduanya dengan hasil akurasi klasifikasi $80 \%$ [6]. Secara khusus belum ada penelitian yang membahas tentang pengenalan pola motif bati pesisir dan batik pedalaman.

\subsection{Kain Tradisional}

\section{TINJAUAN PUSTAKA}

Kain tradisional dianggap sebagai sumber daya dokumenter dimana gambar dari masyarakat digambarkan dengan semua aspek ekonomi, sosial dan psikologis serta manifestasi dari interaksi manusia dengan lingkungannya. Keanekeragaman dalam gaya hidup menghasilkan keragaman dalam kostum, hasil kerajinan dan dekorasi antar suku[7]. Kain tradisional di Indonesia biasanya dibuat untuk memenuhi tujuan ritual agama / kepercayaan tertentu dan biasanya proses produksi adalah bagian dari ritual, mengandung filosofi tertentu tergantung pada asal-usul daerah, orang yang membuat biasanya memiliki ketrampilan yang sudah pada tingkat mahir dan memakan waktu, kain tradisional kaya akan ornamen, warna, motifnya rumit, rinci dan ornament tersebut memiliki nilai - nilai simbolik. Bahan pewarna untuk kain tradisional di Indonesia tidak berbeda jauh dari setiap daerah Pewarnaannya menggunakan bahan yang natural, pewarna ini biasanya dibuat dari kayu, kulit kayu, daun atau akar dari tanaman di seluruh Indonesia. Di masa lalu, tujuan digunakannya serat alami dan pewarna secara tradisional digunakan sebagai bahan agar kain tradisional tersebut terjaga kesuciannya untuk digunakan dalam acara spiritual. Jadi tidak mengherankan jika proses produksi biasanya memakan waktu dan sangat rumit[8], .

2.2 Pengolahan Citra Digital

Pengolahan citra adalah studi tentang algoritma yang mengambil gambar sebagai masukan dan mengembalikan gambar sebagai output. Saat ini pengolahan citra menjadi alat bantu penting dalam banyak cabang ilmu pengetahuan seperti ilmu komputer, teknik listrik dan elektronik, robotika, fisika, kimia, ilmu lingkungan, biologi, dan psikologi.

Pengolahan citra merupakan subkelas dari pemrosesan sinyal. Input dari pemrosesan sinyal adalah gambar dan outputnya pun gambar atau karakteristik / fitur yang berhubungan dengan gambar itu. Saat ini, pengolahan citra berkembang pesat dan banyak penelitian tentang pengolahan citra untuk bidang teknik dan teknik informatika[11][12].

\subsection{Matriks Kookurensi Aras Keabuan Grey Level Co-Occurrence Matrix (GLCM)}

Gray-level co-occurrence matrix (GLCM) merupakan metode dengan menggunakan perhitungan statistik dalam ekstrakasi tekstur citra dimana mempertimbangkan hubungan spasial dari piksel pada citra[13]. GLCM dapat dihitung sebagai berikut. Pertama, tekstur gambar asli D direkuantisasi ke gambar $\mathrm{G}$ dengan mengurangi jumlah tingkat abu-abu, $\mathrm{Ng}$. Sebuah nilai tipikal $\mathrm{Ng}$ adalah 16 atau 32. Kemudian, GLCM dihitung dari $\mathrm{G}$ dengan memindai intensitas masing-masing pixel dan tetangganya, yang didefinisikan oleh dislodgment $d$ dan sudut $\emptyset$. Sebuah dislodgment, $d$ bisa bernilai $1,2,3, \ldots \mathrm{n}$ sedangkan sudut, $\varnothing$ terbatas pada $0^{\circ}, 45^{\circ}, 90^{\circ}$ dan $135^{\circ}[14]$ Matrik GLCM dibentuk dari $\varnothing$ dan offset (parameter arah dan jarak) seperti terlihat dari gambar berikut[15]:

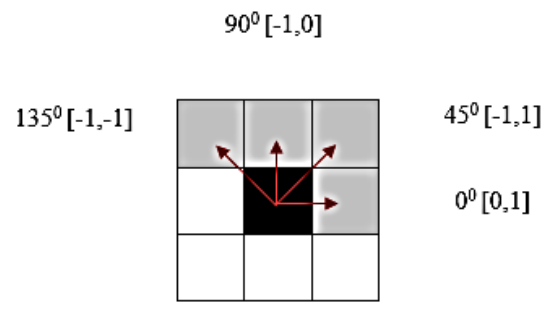

Gambar 1. GLCM dalam ekstraksi fitur 
Beberapa fitur yang dapat diekstraksi oleh GLCM:.

1. Angular Second Moment (ASM)

$$
\mathrm{ASM}=\sum_{i=1}^{L} \sum_{j=1}^{L}\left(\operatorname{GLCM}(i, j)^{2}\right.
$$

2. Kontras

Kontras $=$

3. Inverse Difference Moment (IDM)

$$
\sum_{n}^{L} n^{2}\left\{\sum_{|i-j|=n} \operatorname{GLCM}(i, j)\right\}
$$

$$
\mathrm{IDM}=\sum_{i=1}^{L} \sum_{j=1}^{L} \frac{\left(\operatorname{GLCM}(i, j)^{2}\right.}{1+\operatorname{GLCM}(i-j)^{2}}
$$

4. Entropi

Entropi dihitung untuk mengukur ketidakteraturan grayscale yang ada di dalam citra. Nilai entropi akan tinggi jika elemen-elemen pada GLCM mempunyai nilai yang hampir sama dan milai akan rendah jika kasusnya mendekati nilai 1 atau 0.

Entropi $=$

$$
-\sum_{i=1}^{L} \sum_{j=1}^{L}(\operatorname{GLCM}(i, j) \log (G L C M(i, j)
$$

5. Korelasi

Korelasi merupakan ukuran ketergantungan linier antar nilai grayscale pada citra.

Korelasi $=$

$$
\frac{\sum_{i=1}^{L} \sum_{j=1}^{L}(i, j)\left(G L C M(i, j)-\mu i^{\prime} \mu j^{\prime}\right.}{\sigma i \prime \sigma j^{\prime}}
$$

Dengan

$$
\begin{aligned}
\mu i^{\prime} & =\sum_{i=1}^{L} \sum_{j=1}^{L} i * \operatorname{GLCM}(i, j) \\
\mu j^{\prime} & =\sum_{i=1}^{L} \sum_{j=1}^{L} j * \operatorname{GLCM}(i, j) \\
\sigma j^{\prime} & =\sum_{i=1}^{L} \sum_{j=1}^{L} \operatorname{GLCM}(i, j)\left(j-\mu j^{\prime}\right) 2 \\
\sigma i^{\prime} & =\sum_{i=1}^{L} \sum_{j=1}^{L} \operatorname{GLCM}(i, j)\left(i-\mu i^{\prime}\right)^{2}
\end{aligned}
$$

\section{$2.4 k-N N$}

$K$-Nearest Neighbor ( $k-N N$ atau $\mathrm{KNN}$ ) adalah algoritma sederhana yang menyimpan semua case yang tersedia dan mengklasifikasikan data atau case baru berdasarkan ukuran kesamaan. Itu sebagian besar digunakan untuk mengklasifikasikan titik data berdasarkan bagaimana tetangganya diklasifikasikan. kNN cenderung berfungsi paling baik pada kumpulan data yang lebih kecil yang tidak memiliki banyak fitur. [21].

\section{METODE PENELITIAN}

3.1. Pengumpulan data

Pengumpulan data pada penelitian ini dilakukan dua cara yaitu observasi dan studi pustaka. 


\subsubsection{Observasi}

Dalam penelitian ini data didapatkan dengan cara observasi, pengumpulan data secara observasi didapatkan dari museum dan toko pedagang kain sasirangan, adapun data tersebut seperti berikut:
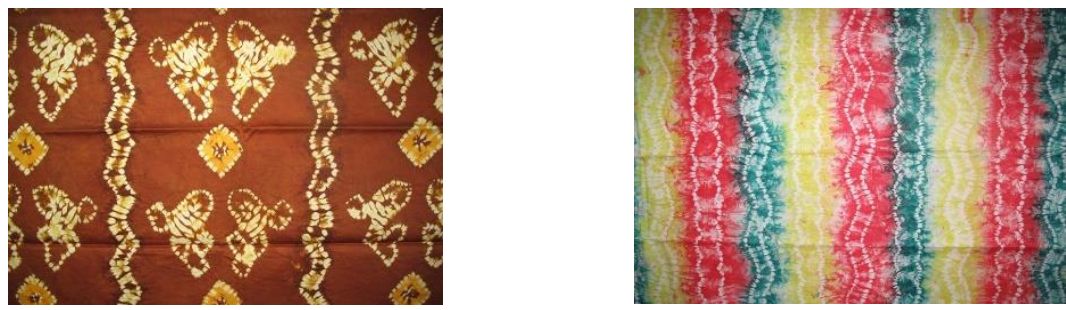

Gambar 2 Citra kain sasirangan

\subsubsection{Studi Pustaka}

Pengumpulan data dalam penelitian ini juga menggunakan studi pustaka yang diambil dari artikel ilmiah, buku, dan lain-lain. Data yang digunakan dalam penelitian ini sebanyak 50 motif kain sasirangan. Untuk eksperimen data akan dibagi untuk training testing.

\subsection{Metode yang diusulkan}

Metode yang diusulkan pada penelitian ini dalam penyelesaian masalah yang telah dipaparkan adalah penerapan sistem pengenalan pola menggunakan fitur ekstraksi Grey Level Co-Occurence Matrix (GLCM) dan algoritma perhitungan jarak euclidean untuk melakukan akurasi membedakan citra motif kaintradisional. Perangkat lunak atau software yang akan digunakan untuk tool pada penelitian ini adalah RapidMiner.

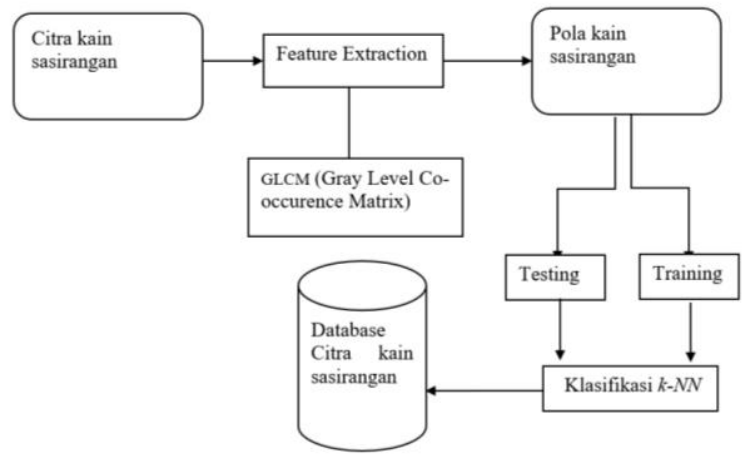

Gambar 3. Model metode penelitian yang diusulkan

Pada Gambar 2 Alur model metode penelian dimulai dari ekstraksi fitur citra kain sasirangan menggunakan fitur ekstraksi GLCM, kemudian setelah melalui proses pengekstrakan citra berubah menjadi pola yang berupa angka. Pola tersebut kemudian diambil 1 data kain sasirangan pada pelatihan untuk dilakukan perbandingan dengan data testing yang tersisa menggunakan perhitungan jarak euclidean untuk mendapatkan hasil akhir. 


\section{HASIL DAN PEMBAHASAN}

\subsection{Data Uji}

Data citra yang digunakan berupa 100 sampel citra, terdiri dari 50 citra sasirangan dan 50 citra kain tradisional bukan sasirangan. Data tersebut akan diklasifikasikan menjadi 2 kelas, ukuran gambar yang digunakan adalah 256x256.

\subsection{Fitur Ekstraksi}

Fitur ekstraksi menggunakan GLCM, langkah pertama untuk menghitung fitur GLCM adalah mengubah gambar RGB menjadi gambar skala abu-abu. Langkah kedua adalah membuat matriks co-occurance dan melanjutkan dengan menentukan hubungan spasial antara piksel tetangga berdasarkan sudut $\theta$ dan jarak $\mathrm{d}$. Langkah selanjutnya adalah membuat matriks simetris dengan menambahkan matriks co-occurance dengan matriks transposnya. Kemudian normalisasi dari matriks simetris dengan menghitung probabilitas masingmasing matriks. Langkah terakhir adalah menghitung fitur GLCM. Setiap fitur dihitung dengan jarak satu piksel dalam empat arah, yaitu yaitu sudut $0^{\circ}, 45^{\circ}, 90^{\circ}$ dan $135^{\circ}$. Gambar 4 adalah hasil rata-rata dari empat arah untuk 10 data awal citra sasirangan.

\begin{tabular}{|l|l|l|l|l|l|}
\hline $\begin{array}{l}\text { No } \\
\text {. }\end{array}$ & ASM & Kontras & IDM & Entropi & Korelasi \\
\hline I. & 0,006151 & 5069,82 & 0,109472 & 9,920064 & $9,32 \mathrm{E}-05$ \\
\hline 2. & 0,020222 & 4508,003 & 0,205158 & 8,485398 & $9,32 \mathrm{E}-05$ \\
\hline 3. & 0,00524 & 1546,059 & 0,124313 & 9,211937 & 0,000147 \\
\hline 4. & 0,000413 & 1267,928 & 0,073154 & 9,83671 & 0,000245 \\
\hline 5. & 0,000155 & 210,6679 & 0,11871 & 9,181421 & 0,000314 \\
\hline 6. & 0,043562 & 1561,627 & 0,3287 & 7,731466 & 0,000121 \\
\hline 7. & 0,000383 & 3986,014 & 0,098428 & 9,930405 & 0,000125 \\
\hline 8. & 0,028108 & 1525,896 & 0,315982 & 8,002012 & 0,000172 \\
\hline 9. & 0,00941 & 7443,419 & 0,15922 & 9,091977 & $6,49 \mathrm{E}-05$ \\
\hline 10. & 0,00014 & 1090,238 & 0,127948 & 9,71382 & 0,000246 \\
\hline
\end{tabular}

Gambar 4. Hasil ekstraksi fitur GLCM

\subsection{Hasil Analisis}

Proses klasifikasi dilakukan dua tahap yaitu training dan testing. Proses training atau pelatihan ini bertujuan untuk melatih sistem. Proses pelatihan hanya dilakukan satu kali. Sistem belum dapat memberikan kesimpulan atau hasil ketika pelatihan belum dilakukan. Proses pelatihan dimulai dengan mengambil gambar untuk dimasukkan ke dalam sistem. Proses selanjutnya adalah melakukan preprocessing. Gambar yang telah dilakukan proses preprocessing, proses selanjutnya adalah mengekstraksi fitur gambar. Proses terakhir adalah menyimpan fitur gambar ke dalam basis data atau ke dalam file. Fitur-fitur data disimpan ke dalam basis data yang akan digunakan sebagai pengetahuan data untuk menentukan kelas dari gambar yang dimasukkan.

Tahapan dalam proses testing atau pengujian tidak jauh berbeda dari yang ada dalam proses pelatihan. Dalam proses pengujian sistem akan memberikan hasil input yang diberikan oleh pengguna. Berdasarkan gambar dari sistem input akan mengklasifikasikan data gambar berdasarkan data pelatihan yang telah dilakukan. 
JTIULM - Volume 04, Nomor 02, Oktober 2019: 43 - 48

\begin{tabular}{|l|l|l|}
\hline iteration & k-NN.k & accuracy \\
\hline 1 & 1 & 0.630 \\
\hline 3 & 5 & 0.540 \\
\hline 2 & 3 & 0.580 \\
\hline 5 & 9 & 0.535 \\
\hline 4 & 7 & 0.530 \\
\hline
\end{tabular}

Gambar 5. Hasil akurasi dari testing data

Gambar 5 menyajikan hasil akurasi pengenalan pola sasirangan mencapai akurasi paling tinggi yaitu 63\% pada iterasi pertama ketika $\mathrm{k}=1$. Sistem pengenalan pola sasirangan masih belum dapat mengklasifikasikan data sesuai dengan kelas gambar kain sasirangan dan kain tradisional. Hal ini dapat disebabkan dari pengambilan data yang tidak konsisten sehingga mempengaruhi kualitas gambar yang akhirnya nilai akurasi belum terlalu baik

\section{KESIMPULAN}

Semakin sulitnya orang dalam membedakan pola kain tradisional karena banyak macam dan jenisnya. Oleh sebab itu dengan penerapan metode KNN dengan ekstraksi fitur ekstraksi Gray Level Co-Ocurence Matriks (GLCM) mampu membantu mempermudah dalam membedakan motif sasirangan dengan kain tradisional lainnya, tetapi masih memiliki kekurangan hasil keakurasian yang didapat dari penelitian ini sebesar $63 \%$.

\section{DAFTAR PUSTAKA}

[1] S. Kartiwa, Ragam kain tradisional Indonesia : tenun ikat. Jakarta: Gramedia Pustaka Utama, 2007.

[2] N. Suciati, W. A. Pratomo, and D. Purwitasari, "Batik motif classification using color-texture-based feature extraction and backpropagation neural network," Proc. - 2014 IIAI 3rd Int. Conf. Adv. Appl. Informatics, IIAI-AAI 2014, pp. 517-521, 2014.

[3] P. Kamavisdar, S. Saluja, and S. Agrawal, “A survey on image classification approaches and techniques,” Int. J. Adv. ..., vol. 2, no. 1, pp. 1005-1009, 2013.

[4] T. Handhayani, "Batik Lasem Images Classification Using Voting Feature Intervals 5 and Statistical Features Selection Approach," pp. 5-8, 2016.

[5] D. Gries and F. B. Schneider, Texts in Computer Science, vol. 42. Verlag London: Springer, 2010.

[6] I. Nurhaida, R. Manurung, and A. M. Arymurthy, "Performance Comparison Analysis Features Extraction Methods for Batik Recognition," Icacsis 2012, pp. 207-212, 2012.

[7] T. N. Al-ajaji, "The Fabrics which are used to made to traditional costumes in Saudi Arabia Abstract :," pp. 1-11, 2013.

[8] D. Widiawati, S. Sn, M. Sn, M. Rosandini, and S. Ds, "Natural Dyes on Indonesian Traditional Textiles - A Case Study: Geringsing Woven Fabric, In Tenganan Pegeringsingan Village Bali -,” pp. 111-120, 2012.

[9] N. M. \& A. H. Setiohardjo, "Analisis Tekstur untuk Klasifikasi Motif Kain (Studi Kasus Kain Tenun Nusa Tenggara Timur),” vol. 8, no. 2, pp. 177-188, 2014.

[10] Departemen Perdagangan Republik Indonesia, Indonesian Women's Fashion: The Inspiration of New Style. Trade Research and Development Agency Ministry of Trade, Republic of Indonesia, 2009.

[11] G. Anbarjafari, "Digital Image Processing," University of Tartu, 2015. [Online]. Available: https://sisu.ut.ee/imageprocessing.

[12] G. Wolberg, "Introduction to Image Processing," Dept. of Computer Science City College of New York, 2017.

[13] A. A. Patil and K. S. Bhagat, "Plants Identification by Leaf Shape using GLCM, Gabor Wavelets and PCA," vol. 37, no. 3, pp. 140-143, 2016.

[14] D. Alzubaydi, "Probabilistic Neural Network with GLCM and Statistical Measurements for Increasing Accuracy of Iris Recognition System," vol. 136, no. 12, 2016.

[15] Y. Sari, F. D. Marleny, R. Ansari, M. Izzana, A. P. Ricardus, and B. Lareno, “Optimasi Conjugate Gradient Pada Backpropagation Neural Network untuk Deteksi Kualitas Daun Tembakau,” pp. 9-10, 2015. 